\title{
LA DESIGUALDAD SOCIOECONÓMICA EN CHILE Y COLOMBIA: UNA APROXIMACIÓN A LOS FACTORES DE CRECIMIENTO Y LAS OPORTUNIDADES DE MEJORA
}

\author{
María Claudia Cuellar Llano \\ Facultad de Negocios, Gestión y Sostenibilidad \\ Especialización en Gestión Empresarial \\ maria_claudia48@hotmail.com \\ Camila Andrea Cuellar Yaguara \\ Facultad de Negocios, Gestión y Sostenibilidad \\ Especialización en Gestión Empresarial \\ mdr_209@hotmail.com
}

\section{Resumen}

El objetivo del presente artículo es mostrar una comparación de los principales índices que miden la desigualdad socio economía en países como Chile y Colombia, así como los factores que hasta la actualidad han determinado la posición que ocupan ambas naciones con respecto a otros países de la región. El referente teórico del documento surge como producto de las experiencias adquiridas en la misión académica realizada para la especialización en gestión empresarial del Politécnico Gran Colombiano al país de chile. De acuerdo con lo anterior, se tomaron variables de desigualdad social según informes o estadística aportada por la Comisión económica para américa latina CEPAL, donde se pudo observar la posición que ocupan ambos países, para luego evaluar las acciones que cada uno de ellos ha realizado para mejorar o mantenerse en el ranking.

La metodología empleada en el presente documento, tal y como lo afirma (Hernandez, Fernández, \& Baptista, 2014), corresponde a una investigación de tipo descriptivo con base en rastreo bibliográfico, teniendo en cuenta los referentes para realizar la medición del concepto de desigualdad, para los países objeto del estudio.

En un primer momento, se pondrán en contexto los determinantes de la desigualdad para las naciones, teniendo presente el contexto para América Latina; en un segundo momento se hará mención a los factores sociales y económicos como determinantes para lograr niveles de desarrollo, tales como las inversiones en educación, satisfacción de primeras necesidades, apoyo a la inversión social en general por parte del estado. En un tercer momento, se muestran indicadores de percepción de corrupción como un factor retardante en la efectividad del accionar del estado en política enfocadas a disminuir la desigualdad, pues como es evidente a mayor corrupción, menor distribución de los ingresos a la población y mayor 
enriquecimiento de un cumulo de personas con poder que solo entre la elite reparten los dividendos producto de los negocios ilícitos en que incurren. En un cuarto y último momento, se muestra como la desigualdad social y económica puede afectar el desempeño de una nación, en ese mismo sentido mostraremos como la visión del direccionamiento de una filosofía económica puede determinar las brechas que se abren en los factores sociales y desarrollo de una nación.

Finalmente, se procederá a generar una discusión entorno a las oportunidades y barreras actuales en la búsqueda de mejorar los índices de desigualdad, para, por último, generar conclusiones sobre el escrito.

\section{Introducción}

El propósito de este escrito es mostrar un referente conceptual y datos comparativos entre los diversos factores que marcan las brechas de la situación de desigualdad entre Chile Colombia, de la misma forma evidenciar como los diferentes factores juegan un papel determinante en el comportamiento socioeconómico de los países de tal forma que se pueda concluir los beneficios o costos que dichas variables han generado a las dos naciones evaluadas.

Los países o gobiernos tienen como objetivos proporcionar beneficios a la sociedad en materia de calidad de vida, tasa de natalidad, ampliar las expectativas de vida y trabajar en mejoras de la educación para así bridar a la sociedad beneficios sostenibles y fomentar una sociedad más equitativa, formada y con capacidad de decisión de forma que se establezcan sinergias que finalicen en nuevas oportunidades e innovación en todos los sectores del país, en ese sentido, "los gobiernos deberían articular programas que tengan ese objetivo" afirman Malagón y García (1994. P. 88).

Y como indica Esguerra (2000) en el artículo La Responsabilidad patrimonial del estado en Colombia como garantía constitucional "En realidad, lo más importante lo verdaderamente importante, como se constató con el tiempo, era que pudiera proclamarse que en torno del concepto de responsabilidad el Estado gravitaban unos derechos fundamentales de los ciudadanos y unos deberes correlativos de las autoridades públicas, vinculados a la necesidad básica de darle permanente protección a la vida, la honra y los bienes de las personas. Más aún, que esos derechos y esos deberes estaban tenían que estar íntima e inseparablemente relacionados con la propia razón de ser del Estado, y debían por tanto formar parte del contrato social" (P. 882).

Al ver el párrafo anterior y al contrastarlo con lo que sucede en la actualidad, se observa como referente de los países de Chile y Colombia, el grado de corrupción y las tasas de gasto en materia de educación diferentes, así como índices de desigualdad que entre uno y otro que son amplios, es por ello que se hace importante adentrarnos en aquellas acciones que 
emprendió Chile como punto de referente y así proponer acciones que puedan ser asimiladas por Colombia, de forma que se brinden alternativas o caminos para poder disminuir las brechas de desigualdad en materia de poder adquisitivo y de género, para así permitir que los ciudadanos perciban al país como una tierra de oportunidades e inclusión.

La metodología utilizada para la elaboración del escrito fue apoyada en consulta bibliografía relacionada con el tema de interés, de igual forma y a fin de sustentar las variables evaluadas se consultó tablas estadísticas de organizaciones regionales, así como mundiales donde muestran indicadores de desigualdad, pobreza, inversión social y percepción de corrupción.

\section{La desigualdad en el contexto económico}

Mundialmente y a lo largo de la historia, la economía y los factores de riqueza han determinado la calidad de vida de los países y sus habitantes, es así como debido a la revolución industrial de mitad del siglo XVIII, abrió las puertas a nuevas tecnologías y conocimientos, haciendo que la sociedad avanzara como conocemos en materia de salud, expectativa de vida, educación e ingreso, todo ello de la mano con las luchas sociales que otorgaron mayores derechos a los trabajadores y ciudadanos, esto conllevo a una mejor y teórica distribución de la riqueza en los países.

América siendo un continente relativamente joven con respecto a los otros cuatro continentes vio todo estos resultados años después, Estados unidos por su cercanía y preponderancia mundial fue beneficiado de este movimiento industrial, no así Latinoamérica que para los años 1800 todavía seguía siendo colonias del imperio español. En este contexto los países latinoamericanos históricamente y palpablemente han estado rezagados en factores económicos y de competitividad, asomándose apenas después de 33 países todos ellos en el continente europeo y asiático. Portal Expansión (2017).

Los países desarrollados han encontrado que la disminución de las brechas sociales o factores de desigualdad han impulsado el crecimiento de las naciones, por tal razón factores como la educación, tecnificación y oportunidades son los pilares de su sociedad, esto, de acuerdo con el Portal Expansión (2016); Allí, se evidencia que los países que invierten por encima del 5\% de su PIB, en inversión educativa tienen altas tasas de crecimiento en sus factores de oportunidades en los ingresos y obtención de bienes.

En contraposición se observa que países con poca inversión social e industrial abren brechas amplias a factores de desigualdad donde solo un puñado de inversionistas poseen el mayor grado de riqueza, frente al gran índice de personas que forman parte de la sociedad, esto confirmado con los resultados de estadísticos y artículos periodísticos tal como se cita en la BBC.

"Es interesante observar que según este articulo el $13.7 \%$ de los propietarios de tierras en Colombia tienen el 77,6\% de las mismas, lo que deduce que los ingresos solo se acumulan 
en este grupo mínimo con respecto a la población general, otro dato que refleja el artículo es que Colombia para la fecha del articulo perdía 10 puntos en términos de acceso a educación, salud y bajos salarios, donde hoy día está ubicado en 265 \$, esto siendo un $58 \%$ menos con respecto a chile, el cual tiene un sueldo mínimo de 456 \$ e inflación de 2,10\%." (Justo, 2016).

Con este panorama y evaluando las variables presentadas se quiere realizar una evaluación comparativa de la economía chilena enfocado en cómo han trabajado económicamente y desde el punto de vista social para disminuir los factores de desigualdad y en que vía está transitando Colombia considerada actualmente como el segundo país de Latinoamérica con mayor desigualdad en la región. (El tiempo, 2017). De acuerdo con el contexto planteado surge la pregunta entorno a sí la desigualdad aun cuando según Smith es un factor inherente a la economía, ayuda a potencializar las oportunidades de desarrollo; o por el contrario Colombia debe luchar con mayor ahínco, de la siguiente forma: ¿de forma integral gobiernoempresa generan sinergias adecuadas para el crecimiento de un País?

\section{La Desigualdad en Chile y Colombia}

El propósito del presente escrito nos permitirá realizar una evaluación de los factores que a opinión de los autores comparando la situación social y económica de Chile versus Colombia han permitido que el primer país evidencie desempeños en indicadores con mayor desempeño a nivel de distribución de recursos, riqueza y por ello disminución de la desigualdad a nivel social de género y étnico.

Las estadísticas muestran que entre 2008 y 2015 la desigualdad en cuanto a la distribución del ingreso per cápita disminuyo según Gentili (El país, 2015) gracias a la importancia y prioridad que le dieron los países miembros a uno de los objetivos de la Cepal que corresponde a desarrollo social.

Lo anterior sucede, gracias a una mejora de los ingresos laborales, donde la mayoría de los países cuentan con políticas activas de generación, formalización y aumento de empleo, en varios países de la región se han realizado importantes inversiones, lo que se traduce en mejoras y en la distribución de los ingresos, aunque con esto no se soluciona del todo el tema de la desigualdad.

La Comisión Económica para América Latina y el Caribe, - CEPAL ha venido trabajando en promover cambios progresivos que generen mayores niveles de producción y equidad en los países de la región, con esto generar equidad de género, es decir y como confirma la CEPAL (2016) que "las mujer hoy día en sus trabajos siguen con ingresos menores que los hombres"(Pág. 130) limitando así su autonomía económica, así como hablamos de desigualdad de género, también tenemos que hablar de otros factores de desigualdad como los étnicos-raciales, protección social, educación, salud, mortalidad infantil, materna, las migraciones de los países latinos a los demás países de América Latina, todos estos factores 
de desigualdad deben generar alertas en los países miembros y crear políticas públicas para garantizar los derechos que conlleven a la igualdad y el bienestar de todos. (Organización de los Estados Americanos - 2015)

Al comparar la desigualdad entre Colombia y Chile podemos encontrar que Colombia es uno de los países más desiguales a nivel Latam (América Latina), (Segovia y Gamboa, 2015) sin embargo, Chile se ha mantenido en temas de desigualdad estable durante los últimos 20 años, ocupando el segundo lugar después de Paraguay con menor índice de pobreza en América Latina.

Según el Banco Mundial utiliza como línea de pobreza extrema a quienes Marchetti, (2016) afirma. "viven con menos de US\$2,50 al día y como línea de pobreza moderada a quienes lo hacen con menos de US\$4."

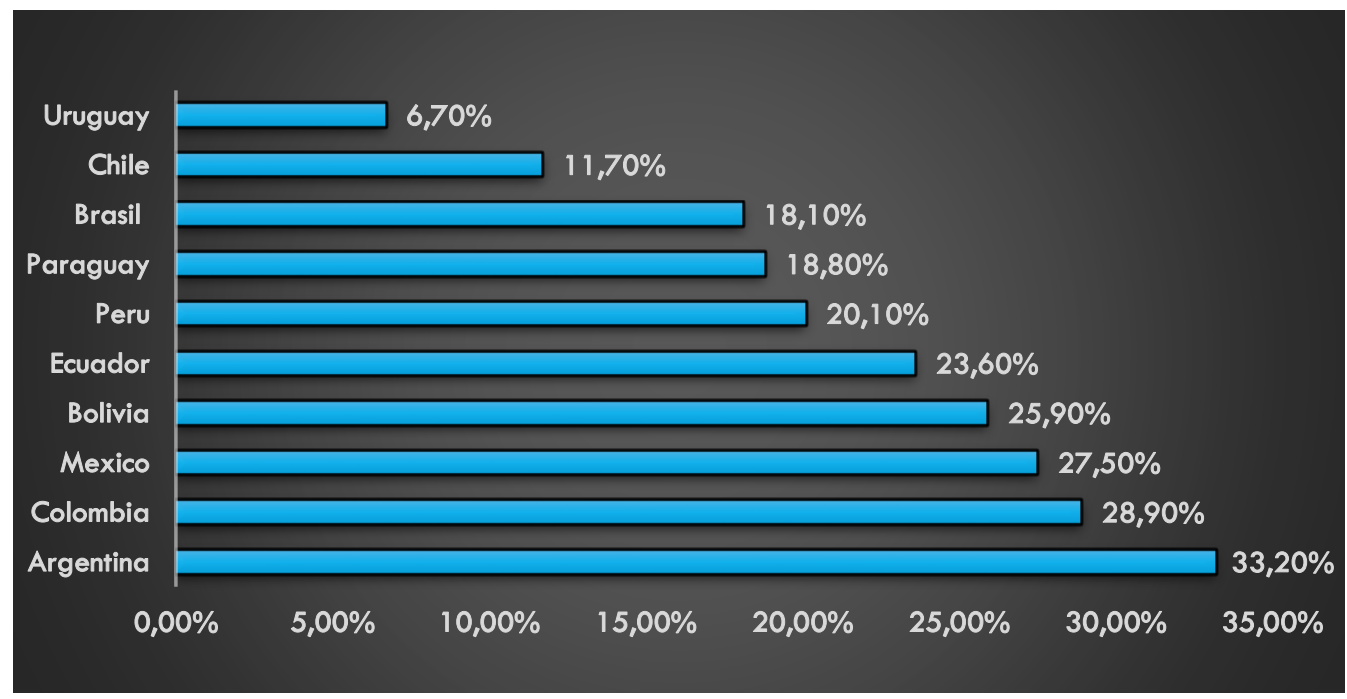

Gráfico 1. Índice de pobreza en Latino América

Fuente: Adaptación Banco Mundial 2014 * Salvo Chile (casen 2015) Argentina (Indec 2016)

\begin{tabular}{lc}
\hline \multicolumn{1}{c}{ País } & Índice \\
\hline Argentina & $33,20 \%$ \\
\hline Colombia & $28,90 \%$ \\
\hline México & $27,50 \%$ \\
\hline Bolivia & $25,90 \%$ \\
Ecuador & $23,60 \%$ \\
\hline Perú & $20,10 \%$ \\
Paraguay & $18,80 \%$ \\
Brasil & $18,10 \%$ \\
Chile & $11,70 \%$ \\
\hline Uruguay & $6,70 \%$ \\
\hline
\end{tabular}

Tabla 1. Índice de pobreza en Latino América

Fuente: Datos suministrados por el Banco mundial en 2014 
La Comisión Económica para América Latina y el Caribe- Cepal considero distintos aspectos como el PIB per cápita, índice de desempleo, índice de precios al consumidor, acceso a vivienda, educación entre otros y de acuerdo con lo anterior la pobreza ha ido en disminución.

Colombia de acuerdo con la Comisión Económica para América Latina y el Caribe- Cepal, es uno de los países con más desigualdad en el mundo y según expertos en temas de pobreza, se cree que Colombia no ha hecho mayor esfuerzo para mejorar la distribución de la riqueza, pero al observar el grafico "incidencia de pobreza en Colombia" ha disminuido su pobreza a través del tiempo, sin embargo, aún sigue con altos índices de desigualdad. (El tiempo, 2016)

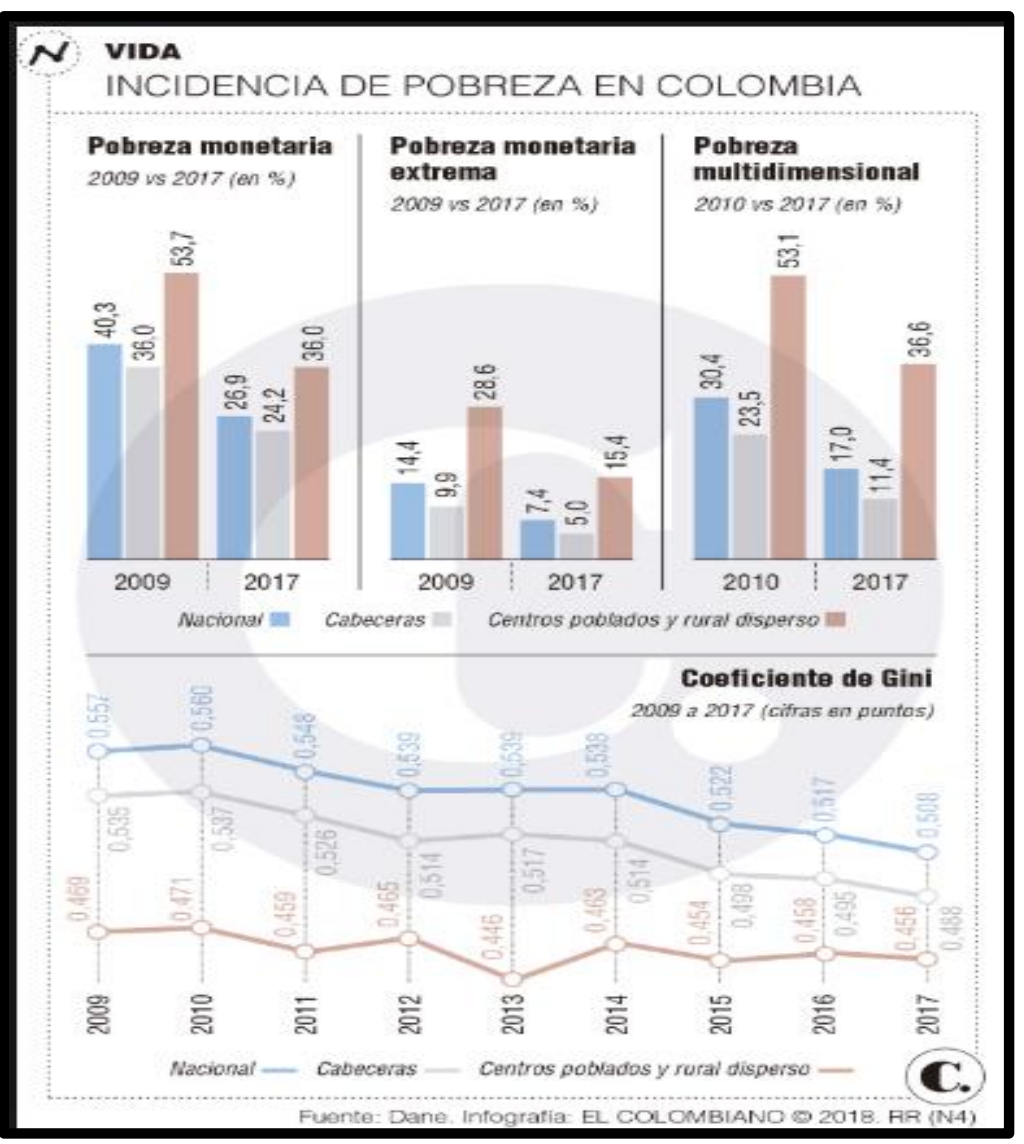

Gráfico 2. Incidencia de pobreza en Colombia

Fuente: Dane. Infografía: EL COLOMBIANO 2018. RR (N4)

Al observar y comparar el Gráfico 1, tenemos que la pobreza por ingresos entre chile y Colombia tienen una diferencia según la fuente de $11,7 \%$ contra $28,9 \%$, dando un gradiente de 17,2\%, (Banco Mundial 2014) la desigualdad tiene mucho que ver con factores como: sistemas tributarios, crecimiento, salud, educación, infraestructura y protección social, esto sustentado en el artículo

"Si se quiere que Colombia siga teniendo un crecimiento económico bueno y sostenido, tiene que haber educación, se tienen que cerrar las brechas entre los ricos y pobres, al menos en lo 
que a acceso a educación de alta calidad se refiere. El país necesita tener capital humano, pero esto, al parecer, en ocasiones sigue siendo tan solo un discurso utópico producto de la fantasía, que dista bastante de la realidad” Revista Divergencia (2017 - pág. 27).

En este sentido se procedió a levantar un cuadro comparativo en cuanto a inversión de las dos naciones tomando como fuente el Banco interamericano de desarrollo a fin de observar el comportamiento obteniendo la siguiente estadística.

\begin{tabular}{lcc}
\hline \multicolumn{1}{c}{ Sector de inversión } & Chile & Colombia \\
\hline Agricultura y desarrollo social & 47 & 82 \\
Educación & 59 & 51 \\
Salud & 16 & 40 \\
Inversiones social & 65 & 103 \\
Trasporte & 23 & 65 \\
\hline
\end{tabular}

Tabla 2. Número de proyectos según sector Fuente: Elaboración Propia

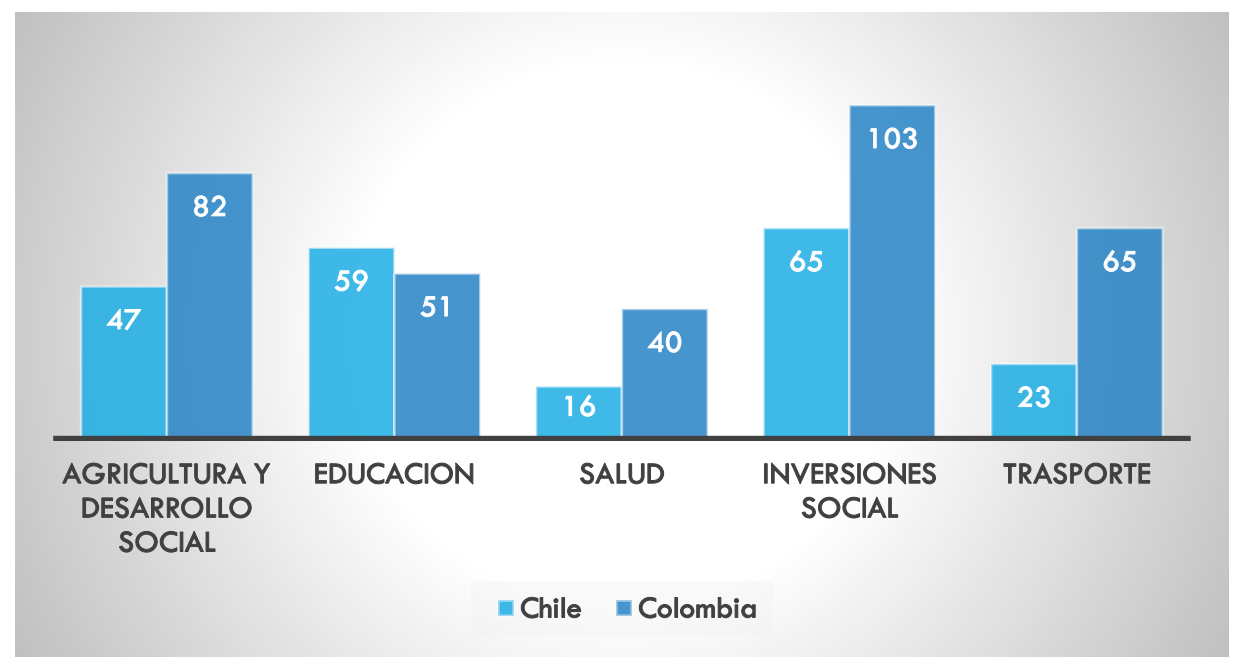

Gráfico 3. Número de proyectos presentados en el BID Chile/Colombia por sector Fuente: Elaboración propia. Adaptado de BID

De acuerdo con el Gráfico 3 respecto al número de proyectos actuales se observa que Colombia está enfocada en elaborar proyectos que satisfacen las necesidades o variables de primer orden para el desarrollo nacional y poblacional, pues la evidencia demuestra un número importantes de proyectos que impactan directamente a la población en factores de bienestar. Ahora si esto es así que sucede que todos estos proyectos no se han traducido en 
factores sociales positivos o consolidados en la nación, por ello se procedió a revisar los índices de corrupción.

Según la organización transparencia internacional, Chile ocupa el quinto lugar del ranking en la percepción de corrupción mientras que Colombia ocupa el puesto 19, siendo superado por Panamá, lo cual es totalmente lógico y sustentado por casos como los Panamá Papers, citando esta organización se llega a las siguientes conclusiones “¿La región se encuentra estancada en la lucha contra la corrupción? Definitivamente no, pero sí es crucial promover un enfoque integral que atienda los problemas estructurales fundamentales, como el financiamiento de la política, las contrataciones públicas y el fortalecimiento de instituciones jurídicas independientes, sólidas y flexibles.” (Transparency International - 2018).

En este sentido de ideas el camino es claro y las estrategias están dadas pero los resultados no se hacen patentes pues en el trayecto de los proyectos el dinero debido a la corrupción desaparece y según la estadística de la distribución de los recursos queda en mano de ese puñado de elite política que domina los recursos adquiridos.

Al revisar el tema tributario se puede analizar que regularmente el gobierno otorga a las empresas y sobre todo a las multinacionales muchas oportunidades para la disminución de impuestos, está perdida de ingresos implica que no pueda haber un financiamiento constante para el crecimiento sostenible, ahora si revisamos el tema tributario en Colombia en la actualidad existe un déficit fiscal que obliga al gobierno a realizar una reforma tributaria que permita suplir el hueco fiscal, pero estas reformas también afectan directamente el bolsillo del ciudadano, pues aumentan los impuestos y esto hace que el ingreso de cada persona disminuya y bueno uno pensaría si los gobiernos implementaran políticas tributarias que refuercen el pago de impuestos pero también reforzaran que la distribución de estos tributos se realizara de manera equitativa y justa, se podría luchar contra la pobreza y desigualdad, impulsando el desarrollo de la economía, generando nuevas fuentes de empleo y mayor eficiencia en el tema de la salud y educación. (Dinero, 2018)

La falta de acceso a la educación de calidad dificulta el desarrollo productivo, debido a la interrupción en el proceso de aprendizaje, desarrollo de capacidades y formación profesional. "En América Latina, una proporción muy significativa de la población mayor de 18 años no alcanza todavía un nivel educativo equivalente al primer ciclo de secundaria completo" confirma la CEPAL (2018 - pág. 124) y esto a su vez genera un efecto negativo para el surgimiento de nuevos sectores innovadores y tecnológicos sobre el sistema económico y competitivo.

Otro tema que destacar es el tema de desigualdad de género y/o étnico-raciales, donde se evalúan los derechos de las mujeres frente a los hombres. Esto dado a que en los últimos años se ha evidenciado una mayor participación laboral y de autonomía económica de las mujeres, pero a pesar de esto, aún se presenta un alto índice de discriminación, inestabilidad y baja remuneración para las mujeres. En el caso de "las mujeres afrodescendientes o indígenas, las discriminaciones pude llegarse a triplicar en comparación a los hombres no indígenas ni afrodescendientes" afirma la CEPAL (2016 - pág. 130) generando así brechas económicas 
en los ingresos de los hogares y barreras en la reducción de la desigualdad y la pobreza. En todo caso aun en nuestros países se sigue viendo discriminación de género, en la siguiente grafica de la Cepal se puede visualizar que los hombres tienen mejores oportunidades salariales que las mujeres con el mismo grado de educación. (CEPAL - 2016).
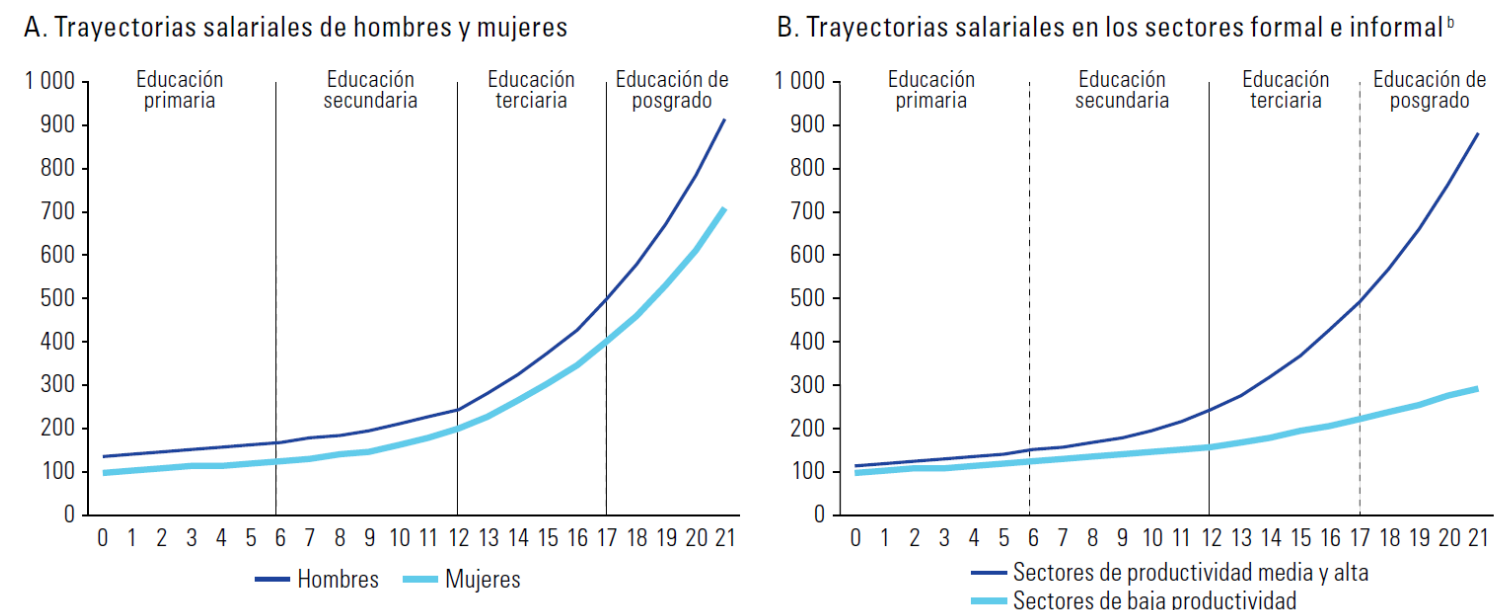

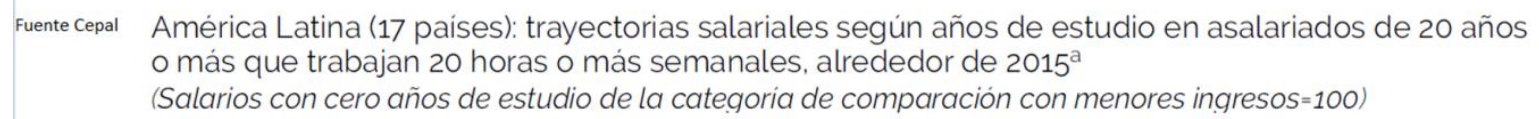

Figura 1. Trayectorias salariales.

Fuente: (CEPAL-2016)

Como plantea la CEPAL (2018) las diferencias de clase y las desigualdades de género, las étnicas y raciales, las relacionadas con las diferentes etapas del ciclo de vida y las territoriales son los ejes de la matriz de desigualdad social de América Latina.” (pág. 136)

La existencia de estas desigualdades implica que el potencial de las personas no se desarrollará plenamente. Habrá un menor estímulo a la educación en el caso de las personas discriminadas y una pérdida de productividad y crecimiento en el conjunto de la sociedad; Es por esto y según la agenda que tiene la Comisión Económica de América Latina y el Caribe para el 2030, el desarrollo sostenible se debe establecer en estrategias políticas y económicas eficaces y eficientes, que permitan estructurar el desarrollo equitativo, continuo y progresivo de los países de América Latina y el Caribe, los cuales tendrán cambios estructurales asociados al Estado, a políticas, a los mercados, al aprendizaje e innovación, al avance e implementación de nuevas tecnologías, logrando aumentar la producción y el empleo a través de la sostenibilidad y la igualdad microeconómica y macroeconómica que reanimaran la inversión, la dinámica económica y competitiva de la región y para que esto funcione y para que la agenda tenga éxito se requiere del compromiso y cumplimiento de cada uno de los países miembros de la Comisión Económica para América Latina (CEPAL)

Así las cosas, se mejoraría la situación entre el Estado, el mercado y la comunidad, generando mayor eficiencia del sistema económico, y se podría establecer de alguna manera una nueva economía de igualdad, donde exista mejor distribución de la riqueza, mayor equidad entre 
género y clases sociales, y no "que el rico se haga más rico y el pobre más pobre", que la educación y la salud sea prioridad en nuestros países, garantizando así mejores oportunidades de crecimiento y desarrollo, más acceso a la salud, menos muertes de madres e infantes y una sociedad más equitativa en todos los aspectos.

En conclusión se puede observar que Colombia con base en sus índices de pobreza y PIB ha mantenido económicamente la teoría del statu quo en la desigualdad con la finalidad de seguir privilegiando a las etites, las cuales finalmente tendrán mayor poder de inversión pero generando lo que se llama una desigualdad estable, caminando en sentido contrario a la corriente de disminución de la desigualdad, caso contrario se evidencia en el caso de Chile como nación en el cual con índices de pobreza de 17\% menor que Colombia, indica la alta inversión en factor social que ha realizado como nación para disminuir los factores de desigualdad y pobreza.

Reafirmando así la teoría económica en el cual una inversión social de los gobiernos en la educación, ingreso per cápita e inclusión social, trae como consecuencia mayor dinamismo a las económicas internas de los países 


\section{Referencias}

Biblioteca congreso nacional https://www.bcn.cl/siit/actualidad-territorial/principales-resultados-sobrepobreza-e-ingresos-regionales-encuesta-casen-2015

BID, detalles del Proyecto, recuperado de: https://www.iadb.org/es/projectssearch? query $\% 5$ Bcountry $\% 5 D=C O \& q u e r y \% 5$ Bsector $\% 5 D=$ TR \&query $\% 5$ status $\% 5 D=\& q u e r y \% 5 B q u e r y \%$ $5 D=$

Carolina Segovia y Ricardo Gamboa (2015) Imágenes de desigualdad en Chile: El impacto de factores económicos y políticos. http://www.scielo.org.co/pdf/papel/v20n2/v20n2a08.pdf

Comisión Económica para América Latina - CEPAL (25 de enero 2016) América Latina y el Caribe es la región más desigual del mundo. ¿Cómo solucionarlo? - https://www.cepal.org/es/articulos/2016-americalatina-caribe-es-la-region-mas-desigual-mundo-como-solucionarlo

Comisión Económica para América Latina - CEPAL - (2016) La matriz de la desigualdad social en América Latina https://repositorio.cepal.org/bitstream/handle/11362/40668/4/S1600946_es.pdf

Comisión Económica para América Latina - CEPAL - (2017) Protección social en América Latina la desigualdad en el banquillo https://repositorio.cepal.org/bitstream/handle/11362/41105/6/S1600819_es.pdf

Comisión Económica para América Latina - CEPAL - Documentos de desigualdad https://www.cepal.org/es/search?as_q=desigualdad

Comisión Económica para América Latina CEPAL - (2018) La ineficiencia de la desigualdad https://repositorio.cepal.org/bitstream/handle/11362/43442/6/S1800059_es.pdf

Comisión Económica para América Latina - CEPAL - (2016) Horizontes 2030 la igualdad en el centro del desarrollo sostenible https://repositorio.cepal.org/bitstream/handle/11362/40159/4/S1600653_es.pdf

Comisión Económica para América Latina - CEPAL - (2018) Agenda 2030 y los Objetivos de Desarrollo Sostenible Una oportunidad para América Latina y el Caribe https://repositorio.cepal.org/bitstream/handle/11362/40155/18/S1700334_es.pdf

José Luis Malagón Bernal y Manuel García Alvares (1994) - Libro: El estado de derecho latinoamericano. Integración económica y seguridad jurídica en Iberoamérica

Juan Carlos Esguerra Portocarrero (2000) La Responsabilidad patrimonial del estado en Colombia como garantía constitucional recuperado de: http://docplayer.es/23835389-La-responsabilidad-patrimonial-delestado-en-colombia-como-garantia-constitucional-juan-carlos-esguerra-portocarrero.html

Marcelo Justo (9 marzo 2016) ¿Cuáles son los 6 países más desiguales de América Latina?, BBC Mundo. https://www.bbc.com/mundo/noticias/2016/03/160308_america_latina_economia_desigualdad_ab.

Ministerio de Desarrollo Social Chile, http://www.ministeriodesarrollosocial.gob.cl/pdf/upload/IDS2017.pdf

Objetivos de Desarrollo Sostenible (ODS) - Colombia https://nacionesunidas.org.co/ods/

Objetivos de Desarrollo Sostenible (ODS) https://www.cepal.org/es/temas/agenda-2030-desarrollosostenible/objetivos-desarrollo-sostenible-ods

Objetivos de Desarrollo Sostenible (ODS) https://www.un.org/sustainabledevelopment/es/poverty/ 
Organización de los Estados Americanos - (2015) Desigualdad e Inclusión Social en las Américas https://www.oas.org/docs/desigualdad/libro-desigualdad.pdf

Organización para las Naciones Unidas para la Educación, la Ciencia y la Cultura (Unesco); https://es.unesco.org/countries/

Patricia Marchetti Michels, (29 de Septiembre 2016) Pobreza en Latinoamérica: Chile se posiciona como el país con menor índice. Portal Emol. http://www.emol.com/noticias/Economia/2016/09/29/824218/Pobrezaen-America-Latina-tras-datos-de-argentina.html

Perfiles latinoamericanos - Revista mexicana de sociología, versión impresa ISSN 0188-2503/ Los estudios sobre la pobreza en América Latina

http://www.scielo.org.mx/scielo.php?script=sci_arttext\&pid=S0188-25032009000500002

Portal Expansión (2016) Gasto público Educación. https://datosmacro.expansion.com/estado/gasto/educacion.

Portal Expansión (2017) Índice de Competitividad Global de: https://datosmacro.expansion.com/estado/indicecompetitividad-global

Portal el Tiempo (26 de marzo 2016) La desigualdad en Colombia es mayor de lo que se piensa. https://www.eltiempo.com/archivo/documento/CMS-16546686

Portal el Tiempo (21 de marzo 2017) Colombia subió al puesto octavo entre países más desiguales del mundo. https://www.eltiempo.com/economia/sectores/indice-de-desigualdad-en-colombia-aumento-segunprograma-de-las-naciones-unidas-para-el-desarrollo-70022

Portal Dinero (15 de enero 2018) Cinco características de la tributaria de 2018 según KPMG. https://www.dinero.com/opinion/columnistas/articulo/colombia-futuro-digital-por-adriana-molano/261561

Programa de las Naciones Unidas para el Desarrollo (PNUD)

http://www.eldesconcierto.cl/2017/10/04/ensayo-sobre-la-desigualdad-encrucijadas-de-la-democracia-en-elcono-sur-americano/

Revista Comisión Económica para América Latina - CEPAL - (2018) La desigualdad disminuye en América Latina en la última década, pero su reducción presenta signos de estancamiento https://www.cepal.org/es/comunicados/la-desigualdad-disminuye-america-latina-la-ultima-decada-pero-sureduccion-presenta

Revista Divergencia No 22 mayo 2017 - Universidad Externado de Colombia file:///C:/Users/mcuella6/Downloads/4860-Texto\%20del\%20art\%C3\%ADculo-21837-1-10-20170427.pdf Revista de la Facultad Latinoamericana de Ciencias Sociales, Sede México - Desigualdad política y desigualdad económica. Entrevista a Adam Przeworsk recuperdado de:

http://perfilesla.flacso.edu.mx/index.php/perfilesla/article/view/744/835

Revista el Clarín - Economía Informe Sobre Desarrollo Económico Y Social La ONU advierte sobre pobreza y desigualdad en América latina https://www.clarin.com/economia/onuadvierte-pobreza-desigualdad-america_O_ryKH6YxnPme.html

Revista Iberoamericana de Educación - Número 23 -OEI - Ediciones - desigualdad educativa en América Latina https://rieoei.org/historico/documentos/rie23a03.htm

Revista Panorámica / desigualdad en América Latina https://www.panoramical.eu/columnas/la-desigualdaden-america-latina-y-el-caribel

Rocio Montes (16 de junio 2017) “Chile no puede insistir en que tiene un 11,7\% de pobres, sino un 20,9\%" El país. https://elpais.com/internacional/2017/06/16/america/1497567774_960351.html 
Transparency International Survey (21 FEBRUARY 2018) No hay cambios en las percepciones pese a los avances en América -

https://www.transparency.org/news/feature/no_hay_cambios_en_las_percepciones_pese_a_los_avances_en_ america 